\title{
Minecraft Learning System for Spatial Reasoning in Middle Grades Learners
}

\section{Dr. Bryce E. Hughes, Montana State University}

Bryce E. Hughes is an Assistant Professor in Adult and Higher Education at Montana State University, and holds a Ph.D. in Higher Education and Organizational Change from the University of California, Los Angeles, as well as an M.A. in Student Development Administration from Seattle University and a B.S. in General Engineering from Gonzaga University. His research interests include teaching and learning in engineering, STEM education policy, and diversity and equity in STEM.

\section{Dr. Nick Lux Lux, Montana State University}

Dr. Nicholas Lux has is an Associate Professor of Curriculum and Instruction in MSU's Department of Education. His teaching and research interests are in the area of educational technology. He has worked in the fields of K-12 and higher education for 18 years, and currently teaches in the Montana State University Teacher Education Program. He has experience in educational technology theory and practice in K-12 contexts and teacher education, with a focus on STEM teaching and learning, technology integration, online course design and delivery, program evaluation, and assessment. Dr. Lux's current research agenda is STEM teaching and learning in K-12 contexts, technology integration in teacher preparation and K-12 contexts, educational gaming design and integration, and new technologies for teaching and learning.

\section{Barrett Frank, Montana State University \\ Dr. SHANNON D WILLOUGHBY WILLOUGHBY \\ Dr. Brock J. LaMeres P.E., Montana State University - Bozeman}

Dr. Brock J. LaMeres is a Professor in the Department of Electrical \& Computer Engineering at Montana State University (MSU) and the Director of the Montana Engineering Education Research Center (MEERC). LaMeres is also the Boeing Professor at MSU where he is responsible for initiatives to improve the professional skills of engineering graduates. LaMeres teaches and conducts research in the area of computer engineering. LaMeres is currently studying the effectiveness of online delivery of engineering content with emphasis on how the material can be modified to provide a personalized learning experience. LaMeres is also researching strategies to improve student engagement and how they can be used to improve diversity within engineering. LaMeres received his Ph.D. from the University of Colorado, Boulder. He has published over 90 manuscripts and 5 textbooks in the area of digital systems and engineering education. LaMeres has also been granted 13 US patents in the area of digital signal propagation. LaMeres is a member of ASEE, a Senior Member of IEEE, and a registered Professional Engineer in the States of Montana and Colorado. Prior to joining the MSU faculty, LaMeres worked as an R\&D engineer for Agilent Technologies in Colorado Springs, $\mathrm{CO}$ where he designed electronic test equipment.

\section{Rachelle Codie Weyerbacher, Montana State University}

Rachelle Weyerbacher is a final semester English Education major from Montana State University with minors in English-Writing and Women Gender and Sexuality Studies. She is an advocate for the usage of technology in the classroom in conjunction with writing across curriculums with a focus on digital literacy. 


\section{Learning from Design: Using Video Game Design Elements to Improve Minecraft Learning System for Spatial Reasoning in Middle Grades Kids}

\section{Introduction}

Increasing the number of people who enter engineering, computer science, and other STEM-oriented fields has been expressed as a national concern over the past two decades as the nation's global economic position has long rested on the robustness of its STEM workforce [1, 2]. One area of interest to policymakers and industry leaders is elementary and middle grades education, where initial aspirations to a STEM career take root through encounters with math and science that can predict later achievement within these fields. Spatial intelligence, or the ability to make spatial judgments and visualize, has been shown to be a strong indicator of middle school students' future achievement in STEM related courses [3-5]. Further, researchers have pointed to spatial intelligence as an explanation for the "gap" between boys' and girls' interest in STEM as spatial intelligence is one of the only areas where boys score differently, and higher, than girls [6]. This spatial intelligence "gap" reinforces stereotypes about gender roles in certain male dominated fields such as engineering and computer science, thus exacerbating the lack of gender diversity in the STEM workforce.

Fortunately, targeted training can significantly improve student ability and close the spatial reasoning gap between boys and girls. Interacting in 3D environments in particular has been shown to assist in the development of spatial reasoning [7-10], and many popular video games today provide 3D environments in which spatial skills may be used. Our project capitalizes on one of the most popular gaming platforms available today, Minecraft, to teach spatial reasoning skills and increase spatial intelligence, because usage of the platform requires building and manipulating 3D objects in a virtual setting. A platform like Minecraft is also a portable, technology-based system that can be easily deployed in a middle school classroom. Most of all, Minecraft is extremely popular, meaning kids may also be motivated to learn spatial intelligence by their excitement to play the game. As such, we designed brief summer camps for middle-school-aged kids in August 2018 and 2019 to test the efficacy of teaching spatial intelligence through the Minecraft platform.

At the conclusion of our first year of camps, we found that kids were not as engaged with the program as we had hypothesized except when offered time for "free play," or time for building and manipulating objects outside of our formally designed spatial reasoning tasks. We determined that the tasks we had designed within the Minecraft environment were too tedious and repetitive, and these tasks too closely resembled the spatial skills assessments we provided the participants to measure changes in their skills. For the second year, we built a "game within the game" to increase student engagement. Utilizing the elements of video game design, in the second year, we embedded spatial reasoning tasks into a fantasy storyline through which kids progressed by completing these tasks.

The purpose of this paper is to explain the process by which we improved a Minecraftbased educational intervention through incorporation of principles of video game design to improve learner engagement. In this paper, we outline the research supporting use of digital 
game-based learning to improve kids' spatial reasoning, the elements of video game design, and the steps we took between years 1 and 2 to improve our Minecraft-based educational intervention. Results from both years are compared to show areas where our intervention improved, and future directions and challenges are outlined based on lessons learned from the process. The outcomes of our project are intended to inform other efforts to employ digital gamebased learning to maximize the utility of this form of leaning for teaching spatial intelligence and other STEM-related skills.

\section{Literature review}

The integration of video games in teaching and learning contexts is often characterized as digital game-based learning (DGBL) [11]. The popularity of DGBL is rooted in educators' attempts to build upon learners' interest in commercial video games, and leverage that interest toward teaching and learning [12]. Consequently, this developing interest in the integration of DGBL is largely due to research suggesting the positive influence of digital games on cognitive learning outcomes and motivational outcomes [13]. Previous studies have found that DGBL is a powerful tool that can influence both cognition and engagement [14].

DGBL provides opportunities for students to participate in situated learning experiences where they can learn by doing [15]. The design of DGBL experiences also aims at providing opportunities for learners to develop cognitive processes, but doing so in such a way that it does not decrease their intrinsic motivation to engage in those processes [16]. In short, DGBL can be a powerful tool for knowledge building, but keeps learners from getting bored with instruction. Further, the integration of these games transcend disciplinary areas and grades levels, with use in contexts from health enhancement to science to mathematics to special education [17-20].

The games employed in DGBL are typically active, experiential, and problem-based, and provide opportunities to practice those skills in a safe environment [18]. These digital games elicit a safe-to-fail environment where students can experiment with solutions to problems without fear of real damage. Successful games place users in "flow states" through balancing their level of skill with progressively increasing challenge, providing clear goals with immediate and unambiguous feedback, and pointing users to relevant stimuli while "backgrounding" irrelevant stimuli into the game environment [21].

Several elements of video game design help explain why digital games are engaging. Video games are fun because they incorporate an appropriate degree of challenge, elements of fantasy that take the user into a fictitious world, and aspects that tap into user curiosity [22]. These types of gaming experiences immerse players and, used in a classroom setting, offer learners a chance for "deep exploration" [23]. Other research has focused more precisely on those common educational video game characteristics, and indicate that DGBL designs often have three primary traits: (1) individuals or groups being in opposition to one another, (2) goal setting, and (3) motivation on the part of the participants [24]. Other common features of DGBL include: 1) a goal or objective; 2) an activity, process, or event (in other words, the player does something); 3) rules that must be followed; and 4) conflict or competition [13]. Immediate feedback has also been found to be central characteristic to DGBL, where learners receive direct 
feedback. This direct feedback allows them to immediately witness the results of their game-play actions [13]. Combined, this previous research suggests that DGBL typically includes some sort of immersion in a fictitious world where objectives must be met, where learners are given immediate feedback, tasked with completing a series of tasks with accompanying objectives, where the intended outcomes are couched in developing students' knowledge, skills, and attitudes. It is these same attributes that were used to guide the redesign of the summer model described in this study.

\section{Using Minecraft for DGBL}

Minecraft is one particular video game that has been co-opted by educators as a mechanism with which to teach across content areas. Minecraft is a blank-canvas world-building game in which users build 3D structures with blocks. The graphics are rudimentary at best, yet the open, flexible, and collaborative design of the game continues to propel interest in Minecraft around the globe, including new efforts to make Minecraft readily available, and safer, for classroom use [25]. Minecraft can be also be employed as an openly collaborative game. Some versions of the game like those with privately-hosted worlds or those provided Minecraft Education Edition allow the teacher to contain the collaboration to the classroom, protecting learners from interacting with only their classmates and not with unknown users playing in the same environment[26]. Collaborative play has been found to be generally more effective than individual play, with single-player competitive games being the least effective for learning gains $[27,28]$. This capacity for collaborative play and learning is a hallmark of Minecraft's integration in the classroom.

During game play, learners move freely about the world that is shaped by predefined environments ranging from water to mountains to forests to prairie-type landscapes. Learners have at their disposal blocks that resemble square bricks that work very much like Legos ${ }^{\circledR}$. The blocks stack on top of one another and connect at the sides and can only be placed in locations that fit within an invisible grid. In some ways, this constraint limits the designer's builds by preventing them from placing the blocks wherever desired. The blocks each have their own physical properties affording learners the ability to create structures and objects with which they and their peers can interact. Learners gather the blocks by "mining" them from the ground or by collecting them from other structures and objects. Learners can even fabricate new objects and tools by "crafting" together found items, creating items like armor, food, wooden planks, or furnaces. Each of these new objects serves important purposes during game play, so learning the art of "mining" the objects and "crafting" new items becomes a core skill for being successful and creative in Minecraft.

Capitalizing on the students' interest in playing Minecraft for fun, creative educators continue to conceptualize different ways in which Minecraft can be used in the classroom to support learning across content areas and grade levels. For example, educators have used Minecraft to support area and perimeter instruction in mathematics, where learners build structures to align with design specifications [29]. High school English teachers have used Minecraft to encourage students' exploration of characterization and plot [30]. The teachers asked that students build narratives in the gaming environment in response to writing prompts, 
and video-record their characters acting in Minecraft, ultimately producing video stories demonstrating their understanding of character and plot development. Science educators have developed complex Minecraft-based lessons for investigating STEM concepts like geology [31]. Since Minecraft building materials often parallel building materials found in the real world, including natural resources like ores, STEM educators use those natural resources in the gaming environment to explore properties of elements. Other teachers have used the immersive sandboxdesign of Minecraft to promote discovery and creativity in their students by designing activities where learners build structures like their dream house [32].

In its native form, Minecraft is a blank-canvas or sandbox program with little structure. Therefore, it does not have the typical built-in mechanisms that most video games use to build engagement such as the need to earn points or complete levels [33]. When integrated in learning contexts, it is the role of the teacher to structure the activity to frame those engaging elements and build learner buy-in. Consequently, our research team synthesized a research-based set of guiding principles to frame the intervention design described in this study. More specifically, we developed a Minecraft-based fictitious world [22] where learners engage in deep and immersive exploration [23]. There are clear and concrete objectives [13] that are to be met by completing a series of activities and puzzles. During game play, learners competed as teams against others to complete a series of puzzles and tasks [24], and were intrinsically motivated to complete tasks couched in the development of cognitive processes [16] like spatial skills.

\section{Process}

The purpose of this project was to address the development of spatial reasoning and to target the difference in spatial reasoning between boys and girls. To achieve this purpose, a portable training system was developed within the popular gaming platform Minecraft to engage students in spatial reasoning activities. This system was tested with learners attending summer camps in 2018 and 2019.

In order to develop the modules in Minecraft, we began with two spatial reasoning tests. The first test was focused on the mental rotation spatial skill, and was based on the Purdue Spatial Visualization Tests: Visualization of Rotations (PSVT) [34] and included the addition of real-world objects and Lego shapes to accompany the original drawn figures in the test. The PSVT test is used to determine the ability of a person to imagine rotating a three-dimensional object. See Figure 1 for an example of an item from the modified PSVT. It should be noted that the original PSVT is an instrument with measured validity and reliability. We recognize that our modification of the item mitigates that reliability and validity. Future research will include validity and reliability measures on this modified PSVT. 


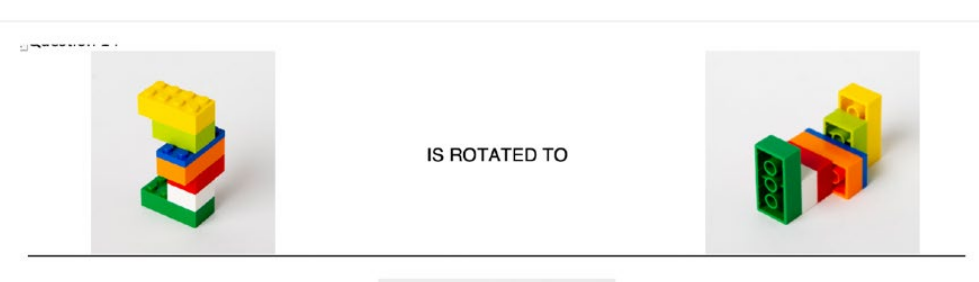

AS

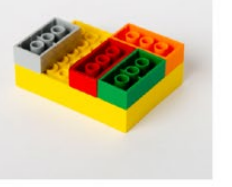

IS ROTATED TO
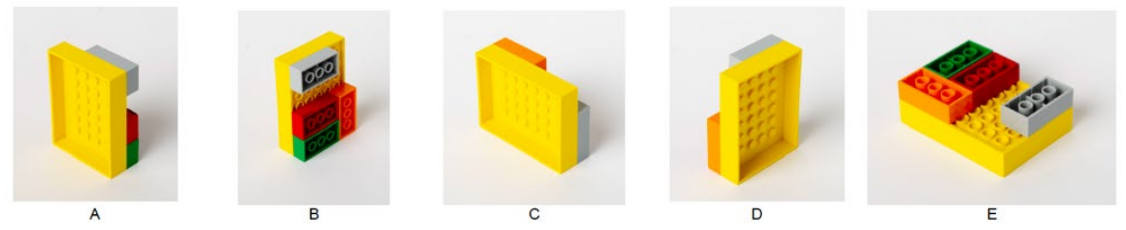

Figure 1. Example item from modified PSVT rotation instrument

8. The diagram below represents a model made of cube blocks.

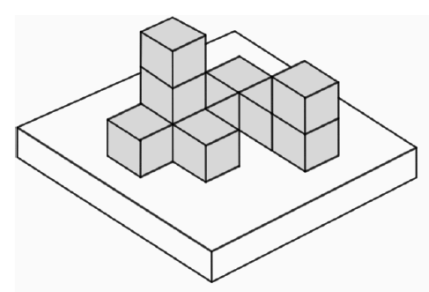

Which one of the following represents the model when viewed from above?
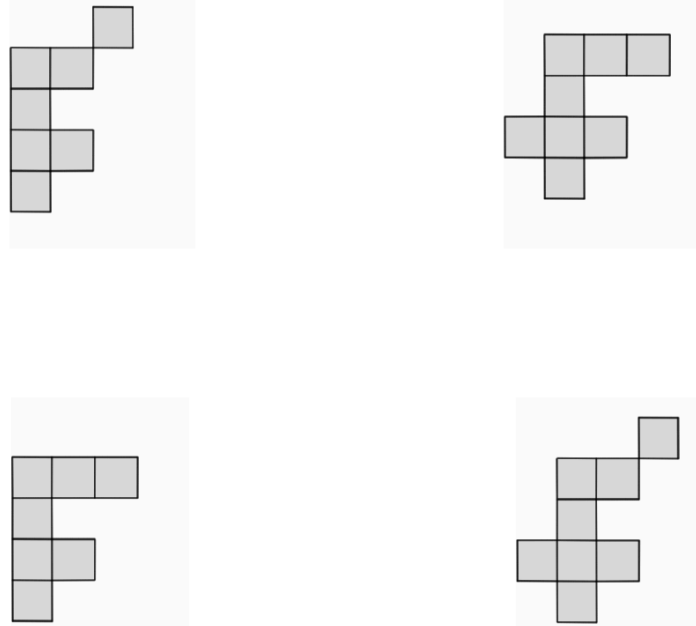

Figure 2. Example item from Spatial Reasoning Instrument [35] 
The second test focused on the 2d-to-3d transformation spatial skill, and was adapted from the Spatial Reasoning Instrument [35] and the Spatial Visualization Test [36]. The 2d-to-3d transformation tests the ability of a person to transform two dimensional representations to three dimensional representations. See Figure 2 (above) for an example of an item from the Spatial Reasoning Test [35] that we added to our modified 2d-to-3d transformation test. Again, it should be noted that this modified instrument has not gone through rigorous validity and reliability measures, and future research will address that limitation.

First, versions of both exams had to be created that could be used with upper-elementary middle school students as several of the tests were originally developed for other age groups. The PSVT was originally developed for use with adults and is most commonly employed in secondary and post-secondary contexts. In consultation with spatial skills experts, the test was adapted for use with elementary learners by reducing the number of item choices and adding in items that used real-world objects. The Spatial Reasoning Instrument [35] was originally developed for K-12 contexts, so little adaptation was needed for it. That test was combined with developmentally appropriate items selected items from the Spatial Visualization Test [36].

These modifications can be done in a few ways; we chose to reduce the number of choices in order to make the tests simpler. This seemed to result in a more developmentally appropriate assessment of spatial reasoning our participants. We were concerned that, had we used the original tests, the difficulty of the tests could overly influence the measurement properties of the instrument. For each question on the exam, we deleted one incorrect option, leaving a total of two incorrect choices and one correct choice. For the Purdue test, we chose to take photographs of actual objects for five of the questions instead of using the original test which has black and white sketches of objects in various rotations. The objects provided in the original test are quite abstract, beyond the level of abstraction kids would be capable of accomplishing. Photographs of objects they were familiar with would be more accessible for them to imagine rotating. This is consistent with the work done to make the Purdue test appropriate for younger children, which also has photographs of actual items. The version for younger children was too easy for our target audience, hence our decision to create our own set of photographs with one correct and two incorrect options. We also reduced the total number of questions on the test, from 30 in the original to 11 on the modified test. This decision was partly a pragmatic decision knowing we would need to implement these instruments quickly during administration of our summer camps.

From the Spatial Visualization Test, we chose three items from this test, and we chose seven items from the Spatial Reasoning Instrument $[35,36]$. These items were combined to create a test of $2 \mathrm{~d}$ to $3 \mathrm{~d}$ transformation that consisted of 10 questions suitable for middle school children.

Once we had determined which tests of spatial reasoning skills we would employ in the study, we developed the Minecraft Modules using a backward design method. To simulate $3 \mathrm{~d}$ rotations within Minecraft, we created several "rooms" in which students would see a set of blocks in one position and in a rotated position. The initial set of blocks involved only one axis of rotation, eventually students would be asked to rotate blocks along two axes. Students would 
"see" two pairs of objects constructed out of blocks. The first pair would demonstrate the rotation by showing the original orientation of the object followed by the rotated orientation of the object. The second pair was incomplete: the first object would be provided, and students would obtain a set of blocks to build what that object would look like rotated similarly to the first pair of objects. Completion of this room would warp them into the next room to continue the activity. See Figure 3 for an overview of a rotation puzzle room.

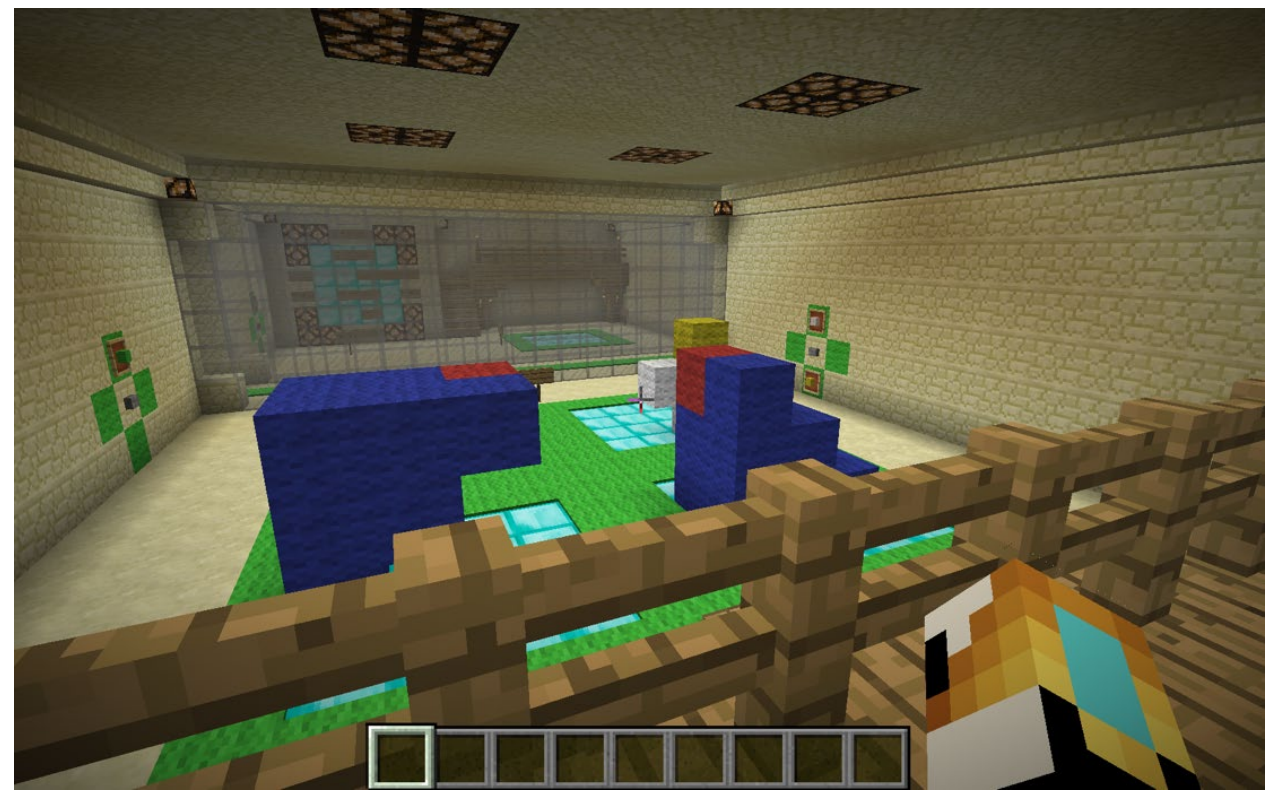

Figure 3. Overview of rotation puzzle room

In order to train students in two dimensional to three-dimensional spatial reasoning, we set up "rooms" where students saw a $2 \mathrm{~d}$ representation of an object on the "wall". The "map," so to speak, showed them where to place blocks, how many to stack on each space, and which sides of the object were up, down, left, and right. Students obtained blocks and created the object in $3 \mathrm{~d}$ space following the plan they observed on the wall, although in harder challenges they were required to rotate the orientation of the object somewhat between its $2 \mathrm{~d}$ representation and their $3 d$ construction. Similar to the first activity, successful completion of each task warped them to the next task. Students were encouraged on both activities to complete as many tasks as possible within the time allotted.

\section{Improvements from year one to two}

At the conclusion of the first camp, results indicated that that participants $(n=27)$ scored higher on the mental rotation post-test than on the pre-test, with a statistically significant increase of 1.0625 points on the 15 -item instrument (95\% CI, -1.6114 to -.5135$) \mathrm{km}, \mathrm{t}(31)=-3.9473, \mathrm{p}<$ .05. Effect size was also calculated with a resulting Cohen's $d$ of approximately .59 , suggesting a medium effect of the treatment. Data analysis of the 2D-to-3D transformation measurement revealed no significant different between pre- and post-test $(0.40625 ; 95 \% \mathrm{CI},-.9391$ to .1266 $\mathrm{km}, \mathrm{t}(31)=-1.5549, \mathrm{p}=.1301)$. Further, when isolated for gender, no significant differences were found between boys and girls. In addition to the discrepant findings on spatial skill growth, 
a key concern that was raised that the spatial reasoning activities were disengaging. These activities, which simulated 2D-to-3D transformation and rotation skills, were designed to capitalize on the 3D world of Minecraft, and learners' spatial reasoning skills did improve from the pretest to the posttest, but our external evaluator found students reported the tutorial-type design of the activities tedious. We also determined the activities to be inappropriate for the age group, despite aligning them with the spatial reasoning tests, as they were quite challenging for kids to complete. These activities may have been appropriate for measuring spatial reasoning, but they were not scaffolded well for teaching spatial reasoning. However, learners reported that free play within the Minecraft environment was considerably more engaging. During free play, students were allowed to roam free within the Minecraft environment and play as they wished, and during many free play sessions students were encouraged to free build structures such as houses.

For year two, we went back to the drawing board and brainstormed how we might make the experience more engaging. We decided to model the activity as a video game, making modifications to the spatial skill interventions in alignment with the what is understood about how video games best engage people. Rather than working kids through modules of spatial skills exercises, we embedded the modules into a storyline to embed elements of fantasy into game play and set clear goals. See Figure 4 for an example page from the storyline.

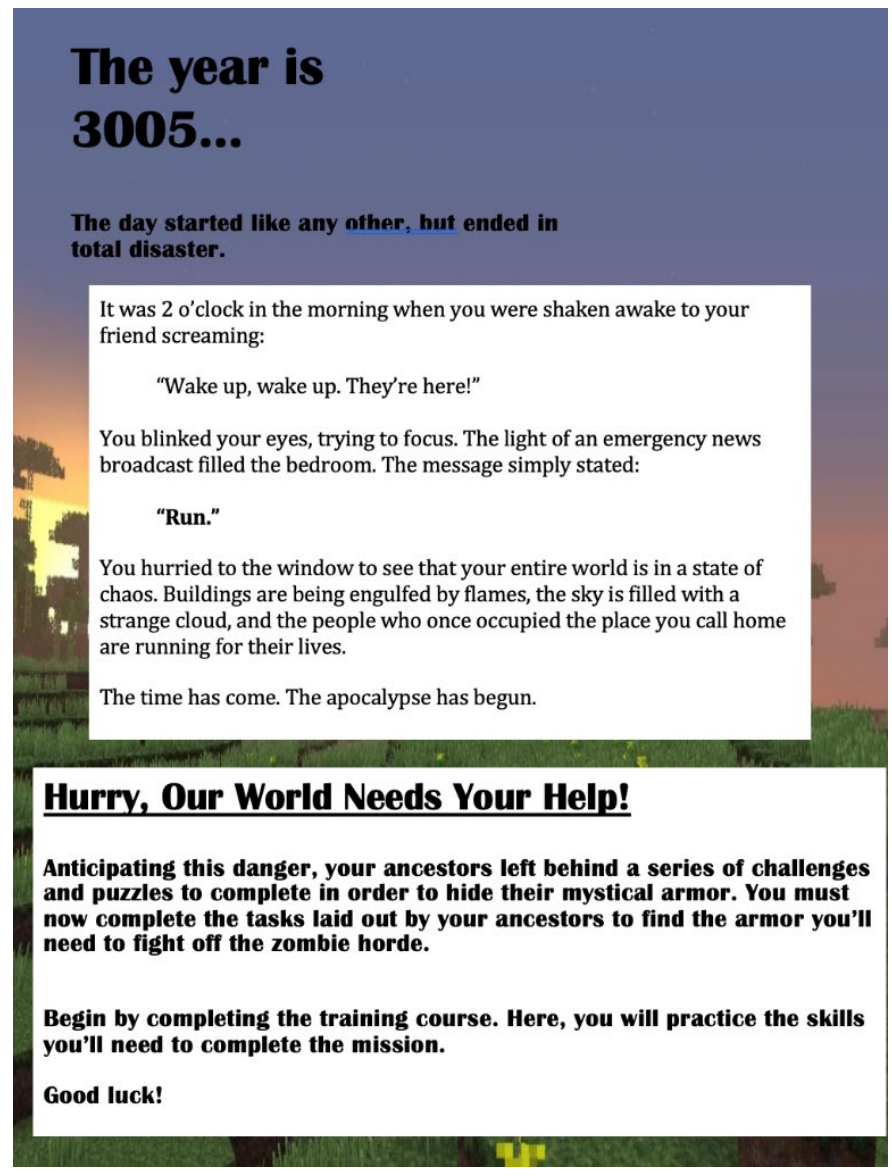

Figure 4. Introduction to the new storyline 
Three stories were proposed; one was to place students in a magical world where they could make potions, another was to save a herd of animals from an impending flood, but the storyline that caught the most interest was escaping a post-apocalyptic zombie horde. At the start of the activity, students were placed in "dungeons" that they needed to solve in order to unlock the various spatial skills modules that provided them items to prepare to ward off the impending zombie invasion. See Figure 5 for an example of the location where participants first started the spatial skills dungeon.

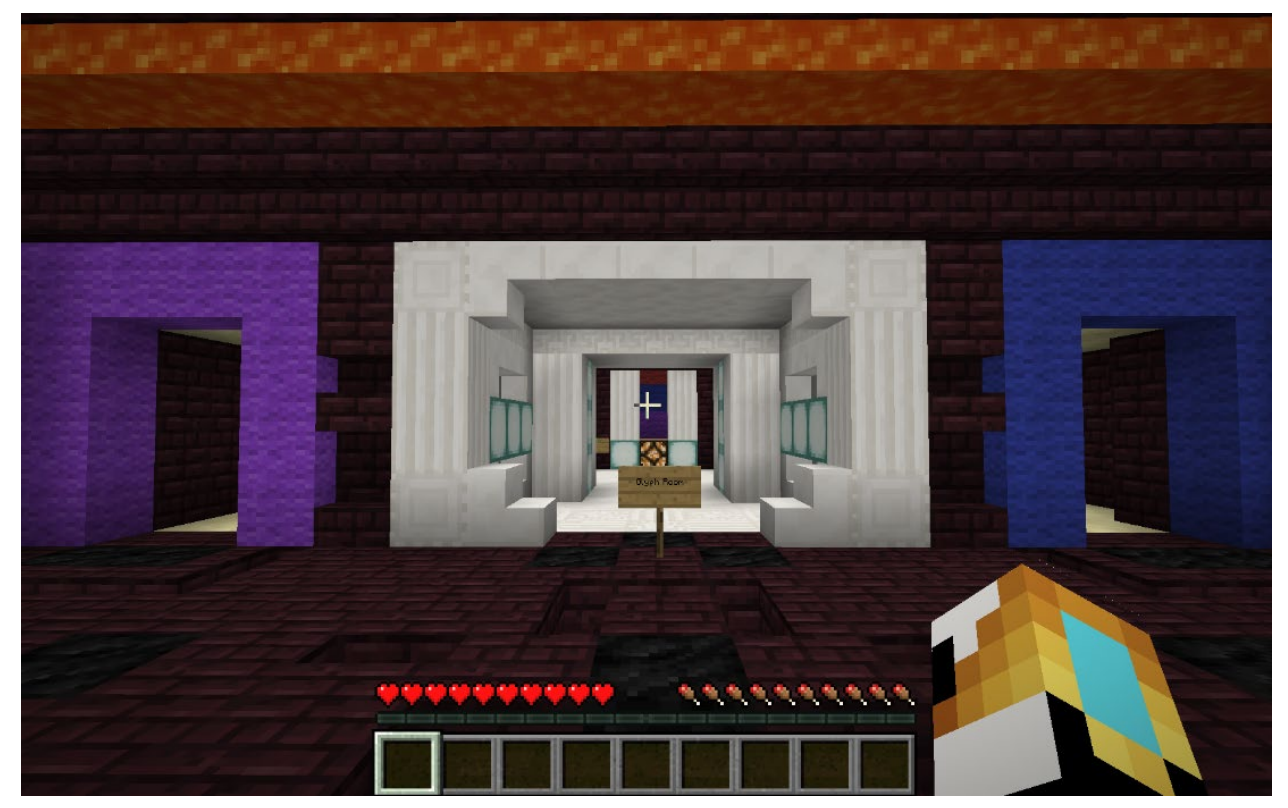

Figure 5. Spatial skills dungeon starting location

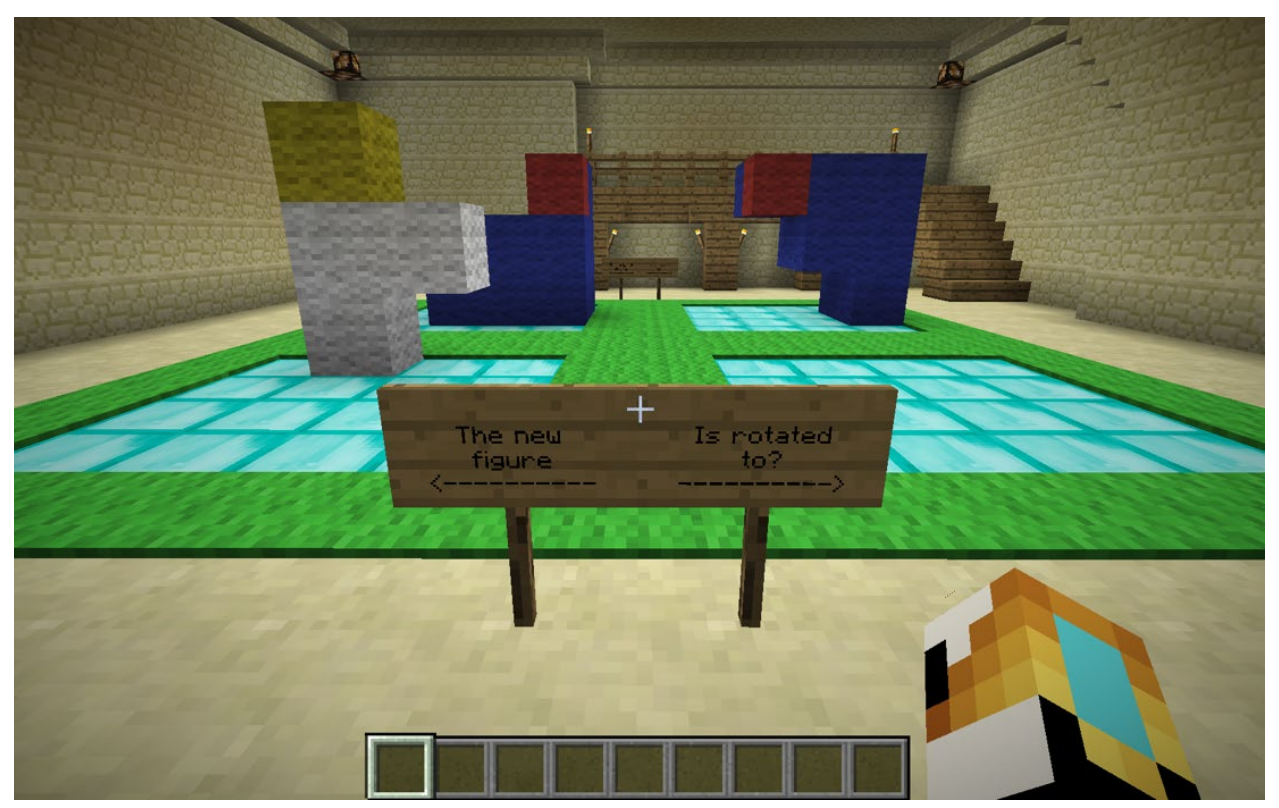

Figure 6. Mental rotation puzzle 
Students first solved two puzzles, the first a rotation puzzle, and the second a $2 \mathrm{~d}-$ to- $3 \mathrm{~d}$ transformation puzzle, in order to receive a map of part of the dungeon, which would provide an opportunity for $2 \mathrm{~d}$ to $3 \mathrm{~d}$ transformation (reading the map to navigate a maze). In order to fully escape the dungeon, students were required to complete five rotations modules and five $2 \mathrm{~d}-$ to- $3 \mathrm{~d}$ transformation modules. See Figure 6 (above) for an example of a mental rotation puzzle.

To motivate them to escape the maze, students were awarded an object, such as armor or a weapon, that would help defend their individual Minecraft avatar against the impending zombie horde. Students were also given an opportunity for free building, but, for this second year, students used free play to build bases to defend against the zombies. A rubric was used to assess students on their free builds. This storyline more appropriately scaffolded activities to provide a reasonable level of challenge, and students were required to work together as teams to increase their motivation through cooperation.

For the second camp, we also completely revamped both tests. In addition to shooting new photographs for the rotations, we also converted the spatial reasoning instrument to a Qualtrics format for assessment purposes. All rotation photos were re-shot in order to improve the clarity of the rotation being completed. Several household objects used on the first test were replaced with Lego replicas of the shapes present in the original PSVT [34]. Each question was also converted to a two-tier question, with the second tier asking students to rate their level of confidence in their answer using a three point scale (very confident, somewhat confident, not confident). The 2d-to-d3 transformation test was altered to include two questions related to map reading, the same second tier set of questions was added, and this test was also converted to a Qualtrics format. Both tests were expanded to include a total of 15 questions each.

\section{Lessons learned}

Although Year 2 post-camp data analysis is still in process, initial findings show that although no significant spatial skill growth was detected, results do suggest that participants were able to solve spatial problems more swiftly. Participants completed the 2D-to-3D test quicker on the post-test $(370.7 \pm 104.8)$ than on the pre-test $(664.2 \pm 278.0)$, with a statistically significant increase in speed of 356.5 seconds, or 5.94 minutes faster (95\% CI, 192.1054 to 394.8456 ) seconds, $\mathrm{t}(24)=5.9750, \mathrm{p}<.05, \mathrm{~d}=1.39$. Further, participants completed the rotation test quicker on the post-test $(393 . \pm 175.4)$ than on the pre-test $(653.7 \pm 235.2)$ for a statistically significant increase in speed of 260.3 seconds, or 4.34 minutes (95\% CI, 173.7806 to 346.9601$)$ seconds, $\mathrm{t}(26)=6.1809, \mathrm{p}<.05, \mathrm{~d}=1.26$

Secondly, data suggests that most students enjoyed most activities, including the storyline structure, embedded spatial skill activities, and practice opportunities within the Minecraft environment. Over $80 \%$ of the students reported enjoying the dungeon chambers, and almost $90 \%$ reported enjoying the maze challenges. Further, the majority of participants liked the theme of the activities "a lot" $(n=18)$, while several liked it "a little" $(n=3)$. These findings suggest that framing the spatial skill interventions in year 2 based on the characteristics of engaging DGBL strategies better supported learner engagement than the year 1 tutorial/drill structure.

Unfortunately, preliminary analysis of the spatial reasoning assessments demonstrates students 
did not improve spatial reasoning at a statistically significant level. Changes in scores on the assessments improved from pre- to posttest, but not significantly. Students did complete these tests quicker after completing the intervention and showed increased confidence in their responses from pre- to posttest. We tested for gender differences, but our data also showed no significant differences in any of our measures by gender. This finding may mean that our camps did not have the intended effect on gender differences we hypothesized, but it also may point to the possibility that not detecting differences meant to some extent we were able to help narrow any noticeable difference.

\section{Future directions and challenges}

As the project heads into its final year, the team has been discussing what steps to take the project in next. The first is to identify a different format from intense, two-day summer camps to implement this intervention. Our goal is to provide a portable intervention that can easily be implemented in a middle school classroom; a full-day program, let alone multiday program, is simply untenable for middle school teachers. On our end, the camps are quite exciting and fun to administer, but they take a great deal of preparatory and behind-the-scenes work that is not sustainable without a significant amount of resources. Running our intervention as a multi-day camp allowed us to try out a host of activities to see what we can learn about what seems to "stick" for our target audience and what might be less useful, but one next step is to start to break down the activities we facilitated into shorter activities to move toward a reproducible curricular "plug-in" for teachers who need to incorporate spatial reasoning into the classroom.

Our second concern, observed mostly in the small increases in spatial reasoning scores observed with our learners, is that a short-term intervention may be less effective than an intervention over a longer period of time. Rather than two full days of spatial reasoning tasks, we hypothesize that working with a smaller group of learners over a longer period of time engaged in shorter-duration activities may more effectively result in growth in spatial reasoning that persists. Smaller groups are easier to manage, and less stressful for the learners involved, and spacing out the intervention also removes concerns regarding the possibility of test-retest effects confounding our assessment of growth in spatial reasoning.

Finally, we intend to explore the possibility of partnership with MinecraftEDU to develop a self-contained package that can be easily disseminated to teachers nationwide. MinecraftEDU is a division within Minecraft (which is published by Microsoft) focused on educational applications of the Minecraft gaming platform. Partnering with MinecraftEDU also removes the need for hosting the Minecraft "world" locally on a computer or server, which we did for our camps, making implementation by most middle school teachers much simpler. Students will also engage in Minecraft in their own "world," which eliminates the dynamics that arise when all learners are operating within the same "world"-namely, students will not have the opportunity to sabotage each other's work. 


\section{Conclusion}

Using Minecraft as a method for improving the spatial reasoning skills of middle school aged kids holds great potential for broadening participation in the STEM workforce. As research shows that development of spatial reasoning skills predicts future success in STEM courses, especially at the college level, this early intervention can ease students onto these pathways before their socialization begins to encourage them to sort their interests on the basis of their gender. In our project, we determined that implementing the elements of video game design into the intervention improved kids' engagement with their learning and helped increase their confidence and speed at solving spatial reasoning tasks. From our experience facilitating two summers of camps featuring multi-day engagement with Minecraft, we recommend educators consider the possibilities of using Minecraft and other digital game-based learning platforms to pique students' interest in STEM. Many of these students will go on to pursue careers in areas of STEM where significant amounts of job openings are anticipated, but hopefully most will be motivated to increase their scientific literacy to increase their engagement in solving humanity's most pressing challenges. 


\section{References}

[1] National Research Council, Rising above the gathering storm, revisited: Rapidly approaching Category 5. Washington, D.C.: The National Academies Press, 2010.

[2] National Research Council, Rising above the gathering storm: Energizing and employing America for a brighter economic future. Washington, D.C.: The National Academies Press, 2007.

[3] N. Veurink and A. Hamlin, "Spatial Visualization Skills: Impact on Confidence and Success in an Engineering Curriculum," presented at the 2011 ASEE Annual Conference \& Exposition, Vancouver, BC, 2011. [Online]. Available: https://peer.asee.org/18591.

[4] E. Towle, J. Mann, B. Kinsey, E. J. O. Brien, C. F. Bauer, and R. Champoux, "Assessing the self efficacy and spatial ability of engineering students from multiple disciplines," in Proceedings Frontiers in Education 35th Annual Conference, 19-22 Oct. 2005 2005, pp. S2C-15, doi: 10.1109/FIE.2005.1612216.

[5] S. A. Sorby, "Educational Research in Developing 3-D Spatial Skills for Engineering Students," International Journal of Science Education, vol. 31, no. 3, pp. 459-480, 2009, doi: 10.1080/09500690802595839.

[6] M. T. Wang and J. Degol, "Motivational Pathways to STEM Career Choices: Using Expectancy-Value Perspective to Understand Individual and Gender Differences in STEM Fields," Developmental Review, vol. 33, no. 4, Dec 1 2013, doi: 10.1016/j.dr.2013.08.001.

[7] R. H. McKim, Experiences in visual thinking. Boston, MA: PWS Publishers, 1980.

[8] D. H. Bowers, \& Evans, D.L, "The role of visualization in engineering design," in NSF Symposium on Modernization of the Engineering Design Graphics Curriculum, Austin, TX, 1990, pp. 89-94.

[9] B. W. Field, "A course in spatial visualization," in 6th International Conference on Engineering Design Graphics and Descriptive Geometry, Tokyo, 1994, pp. 257-261.

[10] S. A. Sorby, \& Gorska, R. , "The effect of various courses and teaching methods on the improvement of spatial ability," in 8th International Conference on Engineering Design Graphics and Descriptive Geometry, Austin, TX, 1998.

[11] M. Prensky, Digital game-based learning. New York: New York : McGraw-Hill, 2001.

[12] A. All, E. P. Nuñez Castellar, and J. Van Looy, "Assessing the effectiveness of digital game-based learning: Best practices," Computers \& Education, vol. 92-93, pp. 90-103, 2016, doi: 10.1016/j.compedu.2015.10.007.

[13] J. C. Huizenga, G. T. M. ten Dam, J. M. Voogt, and W. F. Admiraal, "Teacher perceptions of the value of game-based learning in secondary education," Computers \& Education, vol. 110, pp. 105-115, 2017, doi: 10.1016/j.compedu.2017.03.008.

[14] E. Núñez Castellar, A. All, L. de Marez, and J. Van Looy, "Cognitive abilities, digital games and arithmetic performance enhancement: A study comparing the effects of a math game and paper exercises," Computers \& Education, vol. 85, pp. 123-133, 2015, doi: 10.1016/j.compedu.2014.12.021.

[15] Y.-J. An and L. Cao, "The Effects of Game Design Experience on Teachers' Attitudes and Perceptions regarding the Use of Digital Games in the Classroom," TechTrends, vol. 61, no. 2, pp. 162-170, 2016, doi: 10.1007/s11528-016-0122-8.

[16] A. Hawlitschek and S. Joeckel, "Increasing the effectiveness of digital educational games: The effects of a learning instruction on students' learning, motivation and 
cognitive load," Computers in Human Behavior, vol. 72, pp. 79-86, 2017, doi: 10.1016/j.chb.2017.01.040.

[17] E. Rowe et al., "Assessing implicit science learning in digital games," Computers in Human Behavior, vol. 76, pp. 617-630, 2017, doi: 10.1016/j.chb.2017.03.043.

[18] M. Papastergiou, "Exploring the potential of computer and video games for health and physical education: A literature review," Comput. Educ., vol. 53, no. 3, pp. 603-622, 2009, doi: 10.1016/j.compedu.2009.04.001.

[19] W. Martin, M. Silander, and S. Rutter, "Digital games as sources for science analogies: Learning about energy through play," Computers \& Education, vol. 130, pp. 1-12, 2019, doi: 10.1016/j.compedu.2018.11.002.

[20] E. Fokides, "Digital educational games and mathematics. Results of a case study in primary school settings," Education and Information Technologies, vol. 23, no. 2, pp. 851-867, 2017, doi: 10.1007/s10639-017-9639-5.

[21] R. F. Bowman, "A "Pac-Man" Theory of Motivation: Tactical Implications for Classroom Instruction," Educational Technology, vol. 22, no. 9, pp. 14-16, 1982. [Online]. Available: www.jstor.org/stable/44423699.

[22] T. W. Malone, "Toward a theory of instrinsically motivating instruction," Cognitive Science, vol. 4, pp. 333-369, 1981.

[23] C. J. Stieler-Hunt and C. M. Jones, "Feeling alienated - teachers using immersive digital games in classrooms," Technology, Pedagogy and Education, vol. 26, no. 4, pp. 457-470, 2017, doi: 10.1080/1475939x.2017.1334227.

[24] S. Vandercruysse, M. Vandewaetere, F. Cornillie, and G. Clarebout, "Competition and students' perceptions in a game-based language learning environment," Educational Technology Research and Development, journal article vol. 61, no. 6, pp. 927-950, December 01 2013, doi: 10.1007/s11423-013-9314-5.

[25] C. Thompson. (2016, April 14, 2016) The Minecraft Generation. The New York Times Magazine. Available: http://www.nytimes.com/2016/04/17/magazine/the-minecraftgeneration.html

[26] Minecraft. (2019). Microsoft.

[27] D. B. Clark, E. E. Tanner-Smith, and S. S. Killingsworth, "Digital Games, Design, and Learning:A Systematic Review and Meta-Analysis," Review of Educational Research, vol. 86, no. 1, pp. 79-122, 2016, doi: 10.3102/0034654315582065.

[28] P. Wouters, C. van Nimwegen, H. van Oostendorp, and E. D. van der Spek, "A metaanalysis of the cognitive and motivational effects of serious games," J. Educ. Psychol., vol. 105, no. 2, pp. 249-265, 2013, doi: 10.1037/a0031311.

[29] B. Bos, L. Wilder, M. Cook, and R. O'Donnell, "Learning mathematics through Minecraft," Teaching Children Mathematics, vol. 21, no. 1, August 20142014.

[30] M. Cipollone, C. C. Schifter, and R. A. Moffat, "Minecraft as a Creative Tool," International Journal of Game-Based Learning, vol. 4, no. 2, pp. 1-14, 2014, doi: 10.4018/ijgbl.2014040101.

[31] L. Sharp, "The geology of Minecraft," Teaching Science, vol. 63, no. 1, pp. 14-17, 2017.

[32] M. Checa-Romero and I. Pascual Gómez, "Minecraft and machinima in action: development of creativity in the classroom," Technology, Pedagogy and Education, vol. 27, no. 5, pp. 625-637, 2018, doi: 10.1080/1475939x.2018.1537933. 
[33] N. Callaghan, "Investigating the role of Minecraft in educational learning environments," Educational Media International, vol. 53, no. 4, pp. 244-260, 2016, doi: 10.1080/09523987.2016.1254877.

[34] R. B. Guay, Purdue spatial visualization test: Rotations. . West Lafayette, IN: Purdue Research Foundation, 1977.

[35] T. Lowrie, T. Logan, and A. Ramful, "Visuospatial training improves elementary students' mathematics performance," British Journal of Educational Psychology, vol. 87, no. 2, pp. 170-186, 2017, doi: 10.1111/bjep.12142.

[36] G. Lappen. M. S. University. (1981). Middle Grades Mathematics Project, Spatial Visualization Test. 